\title{
Effect of refrigerator positions on quality of fresh-cut pepper
}

\author{
Y. Ma, C. Zhang, A. Yang, Y. Wang \& X. Zhao \\ Beijing Vegetable Research Center, Beijing Academy of Agriculture and Forestry Sciences; Beijing \\ Key Laboratory of Fruits and Vegetable Storage and Processing; Key Laboratory of Biology and \\ Genetic Improvement of Horticultural Crops (North China), Ministry of Agriculture; Key Laboratory of \\ Urban Agriculture (North), Ministry of Agriculture, 9 Shuguanghuayuan Road, Haidian District, \\ Beijing, China
}

KEYWORD: fresh cut; pepper; refrigerator; texture

ABSTRACT: The effect of refrigerator position in the same layer on the quality of fresh-cut pepper was evaluated. The temperatures of the front and rear in the same layer were different. The front temperature was about $0.5 \mathrm{oC}$ higher than the rear temperature. The soluble solid content of the front pepper was higher than that of the rear pepper, while the Vc content of the front pepper was lower than that of the rear pepper. The texture of the front pepper was similar to that of the fresh pepper. Hence, the front position was a good option for the storage of fresh-cut pepper.

\section{Introduction}

Peppers (Capsicum annuum L.) are welcomed for their appealing and characteristic shape, size, color and flavor (Conesa, et al., 2007a, Conesa, et al., 2007b, Gonzalez-Aguilar, et al., 2004). Pepper is also rich in vitamins as well as in minerals such as potassium and magnesium (Ayranci \& Tunc, 2004, Daood, et al., 1996).

The processing of fresh-cut pepper includes the washing, sterilizing, cutting, packaging and storage. The commercial storage of the fresh-cut pepper was stored at an open refrigerator with an air curtain at $4{ }^{\circ} \mathrm{C}$. The temperature and air flow of the different refrigerator layer was a little difference (Antonia Murcia, et al., 2009, Laguerre, et al., 2005, Laguerre, et al., 2007). The difference would result in a change of the quality and shelf life of the fresh-cut pepper (Laguerre, et al., 2005, Laguerre, et al., 2007). However, the further survey showed that the different position in the same layer was also different, which has not been reported to our knowledge. Consequently, the quality of the fresh-cut pepper in the different position in the same layer was compared based on our previous finding. Specifically, a typical refrigerator was used to simulate the commercial storage the fresh-cut pepper in the sales section. The quality of the stored fresh-cut pepper was monitored and compared in $7 \mathrm{~d}$.

\section{Material and Methods}

\section{Storage of fresh-cut pepper.}

Fresh-cut pepper was prepared by Beijing Yunong Food Processing Co Ltd. (Beijing, China). The fresh-cut pepper was transported to the refrigerator in $12 \mathrm{~h}$ after being processed. The refrigerator (Fudao, Beijing $2^{\text {nd }}$ Commercial Machine Plant, Beijing, China) was set at $4{ }^{\circ} \mathrm{C}$ for the whole shelf life evaluation. The refrigerator had 5 layers with an air curtain, which was widely used in the supermarket. The layer was named as $1^{\text {st }}, 2^{\text {nd }}, 3^{\text {rd }}, 4^{\text {th }}$ and $5^{\text {th }}$ layer from the top to the bottom. A few temperature sensors were placed with the pepper to monitor the temperature of each layer. The quality of the products was evaluated on the $1^{\text {st }}, 3^{\text {rd }}, 5^{\text {th }}$ and $7^{\text {th }} \mathrm{d}$. The fresh-cut pepper of the $1^{\text {st }} \mathrm{d}$ was designated as the control.

\section{Determination of soluble solid content}

The sample was smashed in a HR1861food mixer (Philips, Dongguan, China). An aliquot of $1 \mathrm{ml}$ sample juice was dropped on a pocket digital refractometer (Pal- $\alpha$, ATAGO Co., Ltd., Japan) to measure the soluble solid content. 


\section{Determination of Vc content}

The Vc content of the fruits was determined by an HPLC method (Oms-Oliu, et al., 2009). An aliquot of $25 \mathrm{~mL}$ of the juice was mixed with $25 \mathrm{~mL}$ of a solution containing $45 \mathrm{~g} / \mathrm{L}$ of metaphosphoric acid and 7.2 g/L of dithiothreitol. The mixture was centrifuged at $20,000 \times \mathrm{g}$ for 15 min at $4{ }^{\circ} \mathrm{C}$ and the supernatant was vacuum-filtered through the Whatman No. 1 paper. The sample was then passed through a millipore $0.45 \mu \mathrm{m}$ membrane into an opaque vial and kept at $-80{ }^{\circ} \mathrm{C}$ until being used. An aliquot of $20 \mu \mathrm{L}$ was injected into Agilent 1200 series HPLC (Agilent Technologies, Palo Alto, California) fitted with a reverse-phase C18 Spherisorb® ODS2 $(5 \mu \mathrm{m})$ stainless-steel column $(4.6 \mathrm{~mm} \times 250 \mathrm{~mm})$. The mobile phase was a $0.01 \%$ sulphuric acid solution adjusted to a $\mathrm{pH}$ of 2.6. The flow rate was fixed at $1 \mathrm{~mL} / \mathrm{min}$ and monitored at $245 \mathrm{~nm}$ at $25^{\circ} \mathrm{C}$. Vitamin $\mathrm{C}$ was quantified using a calibration curve based on ascorbic acid pure standards and results were expressed as relative Vc concentration.

\section{Texture analysis.}

The texture of the sample was measured by a TA.XT2i plus texture analyzer (Stable Micro Systems Ltd., Godalming, Surrey, UK). The pepper was place on the test platform with the skin on top. The trigger $(\mathrm{P} / 2,2 \mathrm{~mm}$ cylinder) was compressed to $50 \%$ of the total height with a pre-test speed of 2 $\mathrm{mm} / \mathrm{s}$, test speed of $1 \mathrm{~mm} / \mathrm{s}$, and post-test speed of $2 \mathrm{~mm} / \mathrm{s}$. The maximal force was designated as the hardness of the sample, and number of the peak represent the fragility.

\section{Statistical Analysis.}

Analysis of variance (ANOVA) was used to compare mean differences of the results. If the differences in mean existed, multiple comparisons were performed using Duncan's Multiple Range Test. All analysis was conducted using SPSS for Window Version 19. All experiments were done in triplicates or more.

\section{Results and Discussion}

\section{Effect of refrigerator position on soluble solid content of fresh-cut pepper}

Temperature is the key factor related to the shelf life and quality of fresh-cut vegetables (Mohammed \& Yahia, 2011). A proper temperature will extend the shelf life and hold the original quality of the vegetables (Paull, 1999). Figure 1 presents the temperature fluctuation of the refrigerator in the first day of the storage. Four main fluctuations were presented to defrost. And each defrosting lasted for about $2 \mathrm{~h}$. The temperature fluctuation was repeated as the first day for the whole storage. The temperature of the front was about $0.5{ }^{\circ} \mathrm{C}$ higher than the rear in the refrigerator. This phenomenon resulted from the air flow of the refrigerator.

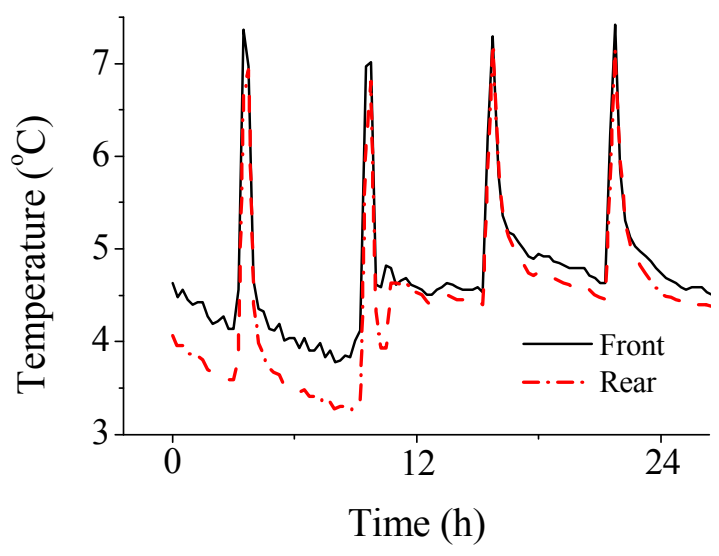

Figure 1 Temperature fluctuation of the refrigerator

The soluble solid content of the pepper is shown in Figure 2. The soluble solid content of the fresh-cut pepper decreased during the $7 \mathrm{~d}$ storage. Especially, the soluble solid content decreased quickly in the $3 \mathrm{~d}$, and kept in about 3.3 in the following days. The soluble solid content reflects the accumulation of the nutrition of the vegetable (Khandpur \& Gogate, 2015). Consequently, the physiological metabolism of the pepper was speculated to be slowed dawn after 3 days' storage. On the other hand, the soluble solid content of the front pepper was lower than that of the rear pepper. The difference was mainly related the different temperature. 


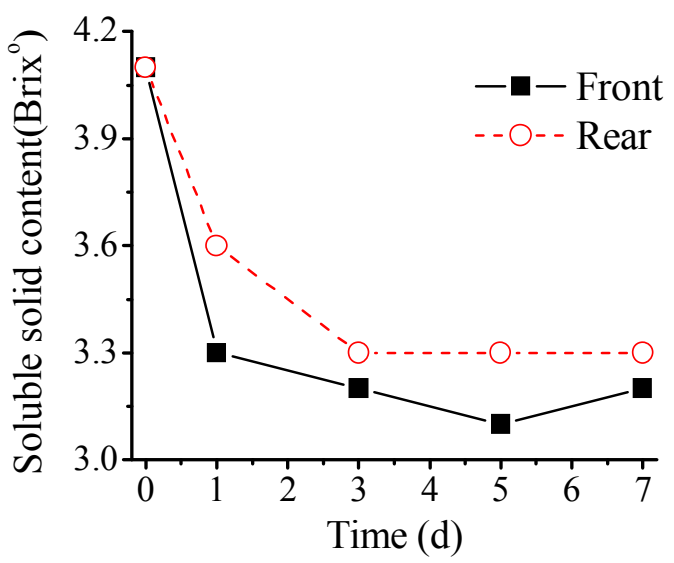

Figure 2 Effect of storage on soluble solid content of fresh-cut pepper

\section{Effect of storage on Vc content of fresh-cut pepper}

Pepper is rich of Vc among all the vegetables(Ayranci \& Tunc, 2004). Vitamin C plays a huge role in maintaining a healthy lifestyle, and preventing disease by its high antioxidant activity (Spínola, et al., 2014). The effect of storage on Vc content of the fresh-cut pepper is shown in Figure 3 . The Vc content decreased quickly in the 3 days' storage, and hold at a constant level. On the other hand, the $\mathrm{Vc}$ content of the front pepper was higher than that of the rear pepper. The Vc is believed to been a stress factor. Both the exterior and inherent stress will enhance the Vc responds (Reuter, et al., 1981). The front pepper was subject to more light, oxygen exposure, and air fluctuation. Hence, the Vc content of the front pepper was higher.

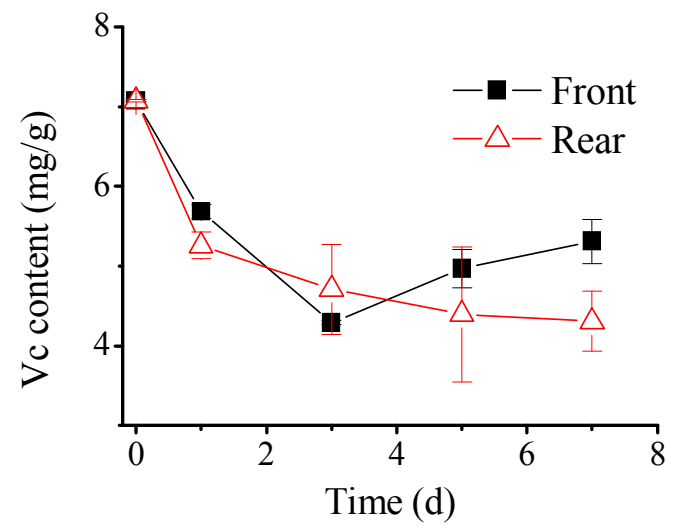

Figure 3 Effect of storage on Vc content of fresh-cut pepper

\section{Effect of storage on texture of fresh-cut pepper}

The effect of storage on hardness and fragility of the fresh-cut pepper is shown in Figure 4. The hardness of the fresh-cut pepper was reduced after $7 \mathrm{~d}$ storage. Moreover, the hardness of the front pepper was higher than that of the rear pepper. Meanwhile, the fragility of the front pepper was similar to that of the rear pepper. Consequently, the texture of the front pepper was similar to that of the fresh pepper.
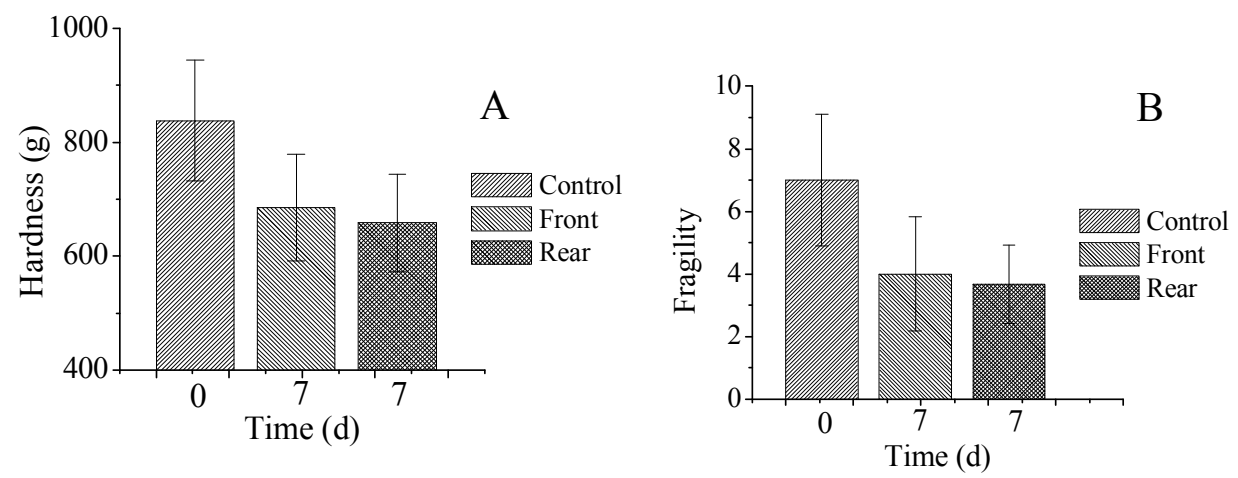

Figure 4 Effect of storage on hardness (A) and fragility (B) of fresh-cut pepper 


\section{Conclusions}

The temperatures of the front and rear in the same layer were different. The front temperature was about $0.5{ }^{\circ} \mathrm{C}$ higher than the rear temperature. The soluble solid content of the front pepper was higher than that of the rear pepper, while the Vc content of the front pepper was lower than that of the rear pepper. The texture of the front pepper was similar to that of the fresh pepper. Hence, the front position was a good option for the storage of fresh-cut pepper.

\section{Acknowledgements}

The authors are grateful to financial support of the earmarked fund for Modern Agro-industry Technology Research System (CARS-26-22 \& CARS-25), Beijing Academy of Agricultural and Forestry Sciences, New Discipline Breeding (KJCX20140204), and Beijing Key Laboratory of Fruits and Vegetable Storage and Processing (Z141105004414037).

\section{References}

[1] Antonia Murcia, M., Jimenez, A.M. \& Martinez-Tome, M. 2009. Vegetables antioxidant losses during industrial processing and refrigerated storage. Food Research International 42(8):1046-1052.

[2] Ayranci, E. \& Tunc, S. 2004. The effect of edible coatings on water and vitamin C loss of apricots (Armeniaca vulgaris Lam.) and green peppers (Capsicum annuum L.). Food Chemistry 87(3):339-342.

[3] Conesa, A., Artes-Hernandez, F., Geysen, S., Nicolai, B. \& Artes, F. 2007a. High oxygen combined with high carbon dioxide improvesmicrobial and sensory quality of fresh-cut peppers. Postharvest Biology and Technology 43(2):230-237.

[4] Conesa, A., Verlinden, B.E., Artes-Hernandez, F., Nicolai, B. \& Artes, F. 2007b. Respiration rates of fresh-cut bell peppers under supertamospheric and low oxygen with or without high carbon dioxide. Postharvest Biology and Technology 45(1):81-88.

[5] Daood, H.G., Vinkler, M., Markus, F., Hebshi, E.A. \& Biacs, P.A. 1996. Antioxidant vitamin content of spice red pepper (paprika) as affected by technological and varietal factors. Food Chemistry 55(4):365-372.

[6] Gonzalez-Aguilar, G.A., Ayala-Zavala, J.F., Ruiz-Cruz, S., Acedo-Felix, E. \& Diaz-Cinco, M.E. 2004. Effect of temperature and modified atmosphere packaging on overall quality of fresh-cut bell peppers. LWT - Food Science and Technology 37(8):817-826.

[7] Khandpur, P. \& Gogate, P.R. 2015. Effect of novel ultrasound based processing on the nutrition quality of different fruit and vegetable juices. Ultrasonics Sonochemistry 27(0):125-136.

[8] Laguerre, O., Ben Amara, S. \& Flick, D. 2005. Experimental study of heat transfer by natural convection in a closed cavity: application in a domestic refrigerator. Journal of Food Engineering 70(4):523-537.

[9] Laguerre, O., Ben Amara, S., Moureh, J. \& Flick, D. 2007. Numerical simulation of air flow and heat transfer in domestic refrigerators. Journal of Food Engineering 81(1):144-156.

[10]Mohammed, M. \& Yahia, E.M. 2011. 20 - Chili plum (Spondias purpurea var. Lutea). Pages 423-437e in Postharvest Biology and Technology of Tropical and Subtropical Fruits. Woodhead Publishing.

[11] Oms-Oliu, G., Odriozola-Serrano, I., Soliva-Fortuny, R. \& Martin-Belloso, O. 2009. Use of Weibull distribution for describing kinetics of antioxidant potential changes in fresh-cut watermelon. Journal of Food Engineering 95(1):99-105.

[12]Paull, R. 1999. Effect of temperature and relative humidity on fresh commodity quality. Postharvest Biology and Technology 15(3):263-277.

[13]Reuter, H.D., Hellriegel, K.P. \& Elis, M.N.G.D.a.J. 1981. Vitamins. Pages 346-350 in Side Effects of Drugs Annual. Vol. Volume 5. Elsevier.

[14] Spínola, V., Llorent-Martínez, J.E. \& Castilho, C.P. 2014. Determination of vitamin C in foods: Current state of method validation. Journal of Chromatography A 1369:2-17. 
